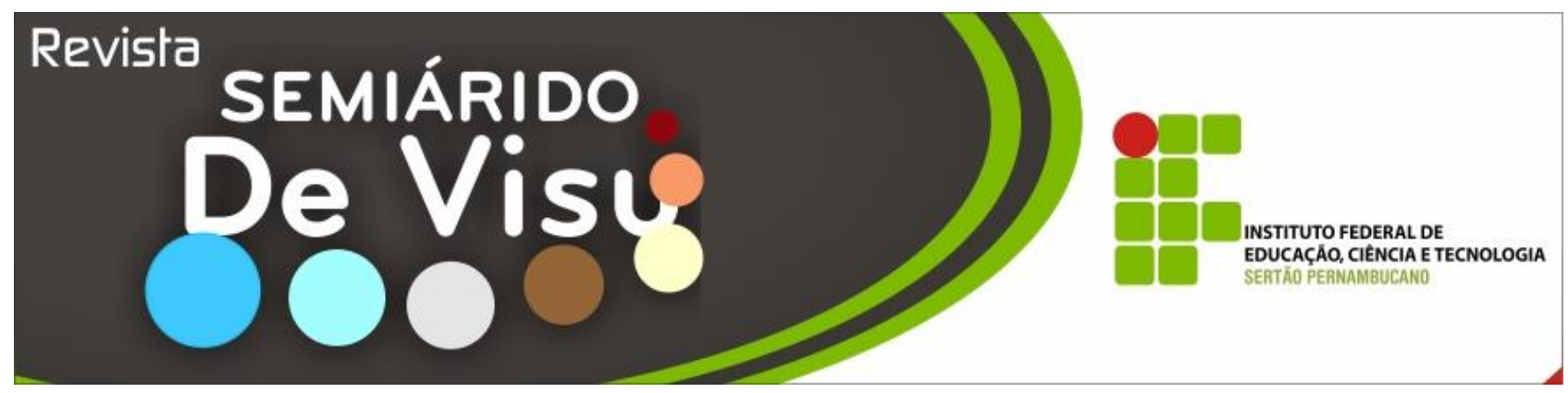

\title{
A visibilidade da gestão do processo de desenvolvimento de serviços na Associação dos Cegos (Fundação João Theodósio de Araújo)
}

\author{
Marcelo Calderari Miguel ${ }^{1}$, Vitorino Fontenele Freire ${ }^{2}$ \\ ${ }^{1}$ Universidade Federal do Espírito Santo (UFES) - Campus Goiabeiras. Avenida Fernando Ferrari, 514, Goiabeiras, Prédio CCJE, \\ Vitória - Espírito Santo - Brasil. CEP 29.075.710 / Telefone: (27) 4009-7744/ E-mail: ${ }^{1}$ <projetoservqual@ gmail.com>; \\ ${ }^{2}$ Universidade Federal do Espírito Santo (UFES) - Campus Universitário de Goiabeiras. Avenida Fernando Ferrari, 514 -Vitória - \\ Espírito Santo - Brasil. CEP 29.075.710 / Telefone: (55 27) 4009-2240/ E-mail: ${ }^{1}$ <vitorino.freire@ caixa.gov.br>.
}

\begin{abstract}
RESUMO: Este estudo de caso pesquisa avalia a qualidade dos serviços prestados na Fundação João Theodósio de Araújo (Associação dos Cegos) de Juiz de Fora, Minas Gerais, utilizando o método de Parasuraman, Zeithaml e Berry, o SERVQUAL. Examina a Matriz Importância X Desempenho como ferramenta para análise dos dados em relação às dimensões da qualidade: Confiabilidade, Empatia, Garantia, Receptividade e Tangibilidade. A metodologia deste estudo possui caráter descritivo de natureza quantitativa. Seu delineamento é do tipo levantamento com a utilização de questionário e da técnica do incidente crítico. Os resultados obtidos nessa pesquisa evidenciam que os clientes consideram a dimensão tangibilidade relevante e, ratificar que a qualidade no processo de desenvolvimento e gestão serviços trata-se de um diálogo desenvolvido e compartilhado entre consumidores e gestores. Recomenda o método SERVQUAL para avaliação da qualidade frente ao modelo filantrópico, realizado entidades beneficentes de assistência social na área de saúde e, assenti como ferramenta útil para a gestão e a tomada de decisões - o qual destaca pontos fortes e fracos das instituições, gerando informações sob a ótica da clientela.
\end{abstract}

Palavras-chave: cidadania, cegos - assistência em instituições, modelo da qualidade de serviços - SERVQUAL

\section{The visibility of the management of the service development process in the Association of the Blind (João Theodósio de Araújo Foundation).}

\begin{abstract}
This study evaluates the quality of services provided foundation JoãoTheodósio de Araújo (Association of the Blind) of Juiz de Fora city, using the method of Parasuraman, Zeithaml and Berry, the SERVQUAL. Examines the Importance Matrix X Performance as a tool for data analysis in relation to the dimensions of quality: Reliability, Empathy, Assurance, Responsiveness and Tangibility. The methodology of this study has descriptive quantitative. Its design is lifting type using questionnaire and critical incident technique. The results obtained in this research show that the customers consider a relevant size tangibility and ratify what quality in development process and management of services this is a dialogue developed and shared between consumers and managers. Recommends SERVQUAL method for assessing the quality of the philanthropic institutions, performed in charitable entities of social assistance in healthcare, we recognize as useful tool for management and decision - which highlights strengths and weaknesses of the institutions, generating information from the perspective of customers.
\end{abstract}

keywords: citizenship, blind - institutional care, service quality model - SERVQUAL 
(MIGUEL; FREIRE, 2017)

\section{INTRODUÇÃO}

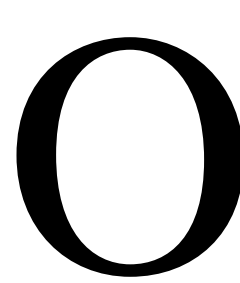

presente artigo aborda o seguinte problema: quais percepções e expectativas têm os clientes (e ou usuários) da Associação dos Cegos (Acegos) de Juiz de Fora, sobre a qualidade dos serviços prestados pelo centro especializados em oftalmologia e pela ótica dessa fundação?

O objetivo principal da pesquisa é avaliar a qualidade dos serviços ofertados em uma entidade oftalmologia que atua na área clínica médico-cirúrgica e assistencial; e apresentar uma adaptação da abordagem teórico-metodológica SERVQUAL como instrumento capaz de aferir à relevância das dimensões da qualidade.

Diante dessa análise, é imprescindível acrescentar que a Acegos, criada em 1939, tem a missão de promover a inclusão do cego na sociedade (sendo uma das mais tradicionais de Juiz de Fora). O lema da entidade é ser a luz dos olhos de quem não a tem. Portanto, a Associação dos Cegos existe não somente para prestar assistência ao deficiente visual, mas também para impedir que outras pessoas fiquem privadas do dom de enxergar.

Cabe destacar que o ano de 2016, marcou os setenta e sete anos de existência dessa entidade pioneira, que trabalha em prol da prevenção da cegueira, da inclusão e desmarginalização de pessoas com deficiência visual - buscando a promoção da inclusão do cego, resgatando-lhe o direito à cidadania.

Vale lembrar que a cegueira compreende a incapacidade de ver devido à perda ou à ausência da percepção dos estímulos visuais e, atinge aproximadamente 45 milhões de pessoas, podendo alcançar uma inquietante projeção de 75 milhões até 2020 (PASCARETTA JÚNIOR, 2008).
Deve-se ressaltar ainda que a ambição da Acegos propende à manutenção e a reabilitação de Práticas Educativas para uma Vida Independente (PEVI) e, visa também à correta confecção e qualidade de óculos em seu departamento de produção ótica.

O presente texto traz uma reflexão sobre a qualidade dos serviços prestados na Acegos, tendo como escopo o atendimento da clínica oftalmológica e do departamento ótico.

Em linhas gerais, pode-se dizer que a noção de serviços é mais claramente vista na consulta clínica e no atendimento desta. Isso justifica nossa escolha para compor o rol de entrevistados, ou seja, aqueles que utilizaram ambos os serviços da associação. Juntamente a essa conjuntura, escolhemos a abordagem teórica metodológica SERVQUAL - a qual reporta que somente é possível avaliar um serviço quem de fato teve contato (prévia experiência) e, encontra-se esclarecido sobre a ambiência, equipe de atendimento - termos que envolvem o marketing holístico.

As considerações finais retomam a análise construída e, responde-se pontos pertinentes as percepções e expectativas reportadas pelos clientes/usuários quanto aos serviços prestados na ambiência da Acegos. Grosso modo, o fio condutor dessa análise é a interpretação da qualidade do serviço percebida pela clientela, a qual gera resultados diante a constatação de hiatos na dimensão da qualidade dos serviços.

Logo, os insights resultantes do diagnóstico SERVQUAL, pode impactar positivamente no processo de gestão e desenvolvimento de serviços da Acegos. Portanto, mais do que meras sutilezas teóricas, esse estudo gera um check-up para enfrentamento da concorrência e melhoria estratégica da entidade.

\section{REVISÃO DE LITERATURA}




\section{Cidadania, transformações e desafios}

A Fundação João Theodósio Araújo, responsável pela Associação dos Cegos em Juiz de Fora, é uma entidade beneficente de assistência social na área de saúde cuja missão é promover a inclusão do cego resgatando-lhe o direito à cidadania e oferecendo-lhe condições para qualificação educacional e profissional. A atuação na área da oftalmologia clínica e cirúrgica tem como alvo a qualidade, bem como, visa um constante aprimoramento nos atendimentos - para a preservação da visão e a prevenção da cegueira. O slogan que acompanhou a história e a evolução dessa associação afirmar que em juiz de fora cego não pede esmola e, desde 1939 busca a entropia negativa - tendo em seus percursos, muitos percalços e grandes dificuldades financeiras.

Os desafios de gestão são muitos, principalmente em tempos que exigem a adoção de uma política econômica "austera". Contra o plano de fundo destas nem sempre silenciosas mudanças, a entidade visa à "prevenção" - sendo, centro de referência de combate ao glaucoma.

Bobbio (1992) preconiza que o problema fundamental em relação aos direitos humanos na contemporaneidade não é tanto o de justificá-los, mas sim, de protegê-los. Portanto, estamos além de uma questão filosófica; o eminente jusfilósofo reporta que o compromisso com a gestão social perpassa por um hodierno ensejo político - que se traduz na questão da tolerância e convivência expressa nos traços estruturais que norteia a perseguição e proliferação dos direitos que desejamos (mediante a intervenção ativa do Estado).

Considerando o contexto apresentado, o propósito investigação ressaltar a profunda simbiose entre a entidade beneficente que atende cerca de quatro mil usuários por mês e oferta consultas/exames e uma ótica que presta serviços à comunidade usuária da Acegos. Em termos de desafios, o entendimento que permeia essa análise engloba diferentes contextos e tendências: de acolhimento, saúde e bem-estar. Levando-se em conta todos esses fatores intrínsecos é de fundamental destacar que na assistência à saúde qualidade é:

[...] um direito do indivíduo e os serviços
de saúde devem oferecer uma atenção que
seja efetiva, eficiente, segura, com a
satisfação do paciente em todo o processo.
O Instituto de Medicina (IOM), dos
Estados Unidos da América (EUA), define
a qualidade na assistência como o grau em
que os serviços de saúde aumentam a
probabilidade de obter os resultados
desejados com o nível de conhecimento
científico atual (BRASIL, 2015).

Segundo os últimos dados (2016) do Ministério da Saúde, a Fundação João Theodósio Araújo, responsável pela Acegos conquistou o Certificado de Entidade Beneficente de Assistência Social (Cebas) na área de saúde. Isso corrobora ainda mais como a tese de que a organização se constitui perante o desafio de empoderar os cidadãos a uma nova realidade biopsicossocial.

Portanto, não se pode deixar de citar que os desafios para a aplicação de uma pesquisa em entidade desse porte, envolvendo um elenco de preocupações, assim sendo, esclarecemos previamente as implicações e impactos da avaliação para todos, em especial, aos respondentes em vulnerabilidade social e, aos interagentes que utilizam e colaboram com a instituição. Urge, portanto, a necessidade de pensar coletivamente junto com a sociedade civil organizada, estratégias de atuação em um cenário de crise econômica e de políticas de austeridade.

Grosso modo, este trabalho torna-se um grande desafio a ser conquistado e mantido ao longo do tempo. Em que, a promoção do bemestar e uma agenda estratégica, que de fato eleja a qualidade como prioritária, ocorre, ipso facto, no plano de um sistema tão complexo como os dos serviços de saúde e assistencialismo. Destaca-se, ainda, que o cuidado centrado no usuário do serviço 
enquadra um amplo rol de atributos para o momento da verdade, tal como: a simpatia, empatia, benevolência, segurança, temperança, capacidade de resposta às necessidades, conhecimento da associação.

\section{Interfaces e projeções da qualidade}

A proposta deste trabalho vislumbra o uso da métrica SERVQUAL em que se infiltrou paulatinamente como instrumento avaliativo no setor de serviços. Conforme Parasuraman, Zeithaml e Berry $(1985 ; 1988)$ a escala mede a amplitude/discrepância entre as percepções (desempenho percebido) e as expectativas dos clientes/usuários (desejos). Assim sendo, há varias pesquisa que evidenciam a correspondência entre a satisfação e a retenção de clientes, uma vez que expandir o status de satisfação pode defluir na aquiescência do ânimo de repetir a experiência de um serviço.

Em linhas gerais, a "qualidade" pode ser conceituada em distintas formas. Nesse estudo escolheu-se o conceito de Parasuraman, Zeithaml e Berry (1985; 1988), os quais: afirmam que a qualidade é a diferença entre as expectativas (esperado) dos clientes sobre o serviço a receber e suas percepções (percebido) sobre os serviços efetivamente entregues. Ainda assim, quando se trata de serviços é necessário atender a critérios desejáveis por aqueles que recebem o serviço. Posto isto, a qualidade dos serviços prestados por entidades depende de conhecimento das expectativas e necessidades dos seus clientes/usuários.

Mello et al. (2010) reporta que a métrica SERVQUAL é composta por 22 questões, que avaliam as expectativas e as percepções, perante as cinco dimensões que envolve a questão da qualidade de serviços (tangibilidade, confiabilidade, responsividade, garantia e empatia). No final, a avaliação da qualidade do serviço é obtida pela comparação dos valores das expectativas e das percepções (MELLO et al., 2010, p.177).

Juran (1994) reporta que um serviço ou produto será de qualidade quando for adequado à utilização pretendida. Todavia, essa definição pressupõe que antes de oferecer um serviço ou produto, existe uma reflexão implícita ou explícita sobre as necessidades e expectativas que ele tenciona atender. De igual maneira, quando se fala da interdependência do cliente para julgar o produto ou serviço, por exemplo, estamos diante do ponto nevrálgico pesquisado por Deming (1994), Juran (1994) e Ishikawa (1997).

Qualidade é um termo multidimensional, por ter significados de natureza objetiva e subjetiva, e por variar de acordo com grupos de interesse e seus atores (multidimensionalidade intrínseca), bem como da sua relação com o programa ou serviço em questão (multidimensionalidade extrínseca). Apesar disso, a percepção sobre atributos de qualidade de determinado produto ou serviço sempre foi realizada pelo homem [...] O conceito de qualidade começa a ser delineado, no início do século passado. A estatística é incorporada ao movimento pela qualidade, e Deming e Juran surgem com a noção de qualidade de forma mais elaborada (BRASIL, 2015).

Nesse contexto, pode-se inferir que o conceito de qualidade que começa a ser delineado é resultado da comparação das percepções com as expectativas dos clientes. Fica evidente, então, que a verificação da qualidade requer certos cuidados e definições precisas, caso contrário não se percebe desafios e vicissitudes que compõem esse conceito.

Confiabilidade: A capacidade de prestar o serviço prometido de modo confiável e com precisão. Tangíveis: A aparência física de instalações, equipamentos, pessoal e materiais de comunicação. Sensibilidade: a disposição para ajudar o cliente e proporcionar com presteza um serviço. Segurança: O conhecimento e a cortesia de empregados e sua habilidade em transmitir confiança e confiabilidade. 
Empatia: A atenção e o carinho individualizados proporcionados aos clientes (BERRY; PARASURAMAN, 1992, p. 30, grifos nossos).

Ainda que haja consonâncias entre os estudiosos da qualidade não é nexo que se reproduz, in totum, Deming (1994) e Juran (1994) asseveram que a percepção de qualidade é frequentemente influenciada por nossas necessidades, expectativas de resultado, desejo, experiências prévias, estado emocional e cognitivo.

\section{MATERIAL E MÉTODOS}

\section{Perspectivas epistemológicas}

A presente investigação teve por objetivo examinar o pacote de serviços da Associação dos Cegos, o conjunto de mercadorias e serviços ofertados pela instituição que desencadeia ações de qualidade.

Nossa proposta é analisar também as interfaces desse pacote de serviços e suas cinco características: 1) instalações de apoio: os recursos físicos necessários para oferecer um serviço; 2) bens facilitadores: os materiais adquirido ou consumido pelo cliente; 3) informações: a informação disponibilizada pelo cliente ou pelo fornecedor e que permite um serviço eficiente e customizado, tal como prontuários e o site institucional; 4) serviços explícitos: os notáveis benefícios prontamente percebidos pelo cliente, que representam características essenciais de um serviço; e os 5) serviços implícitos: aqueles benefícios psicológicos sentidos apenas vagamente pelo cliente.

Para funcionar o sistema de serviços deve-se interagir com os clientes a ponto que estes sejam participantes do processo, considerando que esses aparecem conforme sua própria vontade. Por tal motivo, encontra-se singularidade no processo de serviço que estão descritas a seguir: a) participação do cliente no processo: é importante a presença do cliente para a criação de valor nas empresas e, cada vez mais fica evidente que não basta as organizações estarem direcionadas ao atendimento das necessidades de seus clientes, elas carecem de uma transformação para além deste posicionamento aprendendo a explorar a interação com os seus clientes no processo de criação de valor; b) simultaneidade: os serviços não podem ser estocados, pois são criados e consumidos simultaneamente; perecibilidade: o serviço é perecível pois está relacionado com a necessidade do cliente; d) intangibilidade: os serviços são intangíveis e o cliente precisa confiar na reputação da instituição e; e) heterogeneidade: a natureza intangível dos serviços, aliada ao papel do cliente como participante no sistema, resulta em uma variação dos serviços de cliente para cliente. Segundo Mello e colaboradores (2010) prover serviços de alta qualidade parece ser um pré-requisito para o sucesso, ou para a sobrevivência, das organizações de serviço a partir da década de 80 .

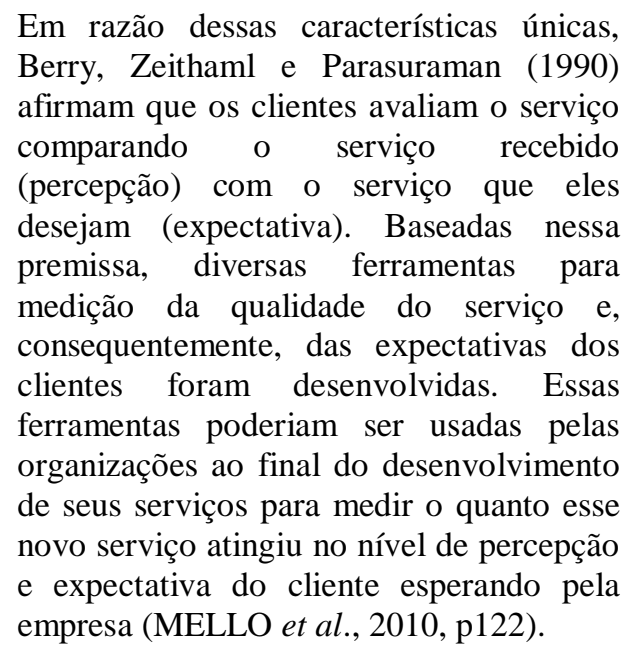

Participaram do estudo 181 pessoas, entre os dias dez e trinta de setembro de 2016, nos períodos matutino e vespertino. Sendo noventa cinco mulheres e oitenta e seis 
homens, que frequentam ou utilizaram os serviços da clínica e da ótica na Associação dos Cegos da Fundação João Theodósio de Araújo. A coleta dos dados ocorreu no mês de outubro de 2016, pelo período de 15 dias. Os finais de semana foram excluídos pelo caráter contribuir um viés do estudo e; amostra considerada é não probabilística e se deu por conveniência; correspondendo disponibilidade dos respondentes entre os horários preestabelecidos: pela manhã, das $7 \mathrm{~h} 30 \mathrm{~min}$ às $11 \mathrm{~h}$; e à tarde, das $14 \mathrm{~h}$ às $17 \mathrm{~h} 30 \mathrm{~min}$, em frente a referida instituição e, após terem utilizado o/os serviço/serviços.

\section{Procedimentos metodológicos}

A pesquisa tem caráter quantitativodescritivo com a utilização de um questionário semiestruturado e não disfarçado, elaborado a partir de um pré-teste, utilizando a abordagem teórico-metodológica SERVQUAL (Service Quality Gap Analysis), sugerido por Parasuraman, Zeithaml e Berry (1985). Tal abordagem torna exequível avaliar a qualidade numa conjuntura em que os serviços prestados podem diversificar. Cada indivíduo retrata jeitos, características e polaridades próprias de acolher e recepcionar, modos de se colocar à disposição, de compreender, de ser e fazer singulares.

Utilizamos, na coleta de dados, três tipos de abordagens: a observação participante, a entrevista semiestruturada tal e qual a utilização da técnica de incidente crítico e, por fim, a adaptação da abordagem teórica metodológica SERVQUAL. A observação participante quanto técnica de abordagem foi fruída por ser sensível as peculiaridades da situação, dado que ela é independente do grau de conhecimento e da capacidade verbal dos sujeitos possibilitando checar, na prática, a sinceridade de certas argumentações dos entrevistados e possibilitar o registro temporal.
Mas, por que denominamos o SERVQUAL como uma abordagem teóricometodológica? Pelo fato de proporciona um corpus teórico sobre imensuráveis conceitos, tais como: qualidade, satisfação, percepção, expectativa, serviços, entre outros conceitos. Outrossim, propõe uma metodologia científica hábil de levar à concretização de diagnósticos que tenha como objeto de estudo a satisfação da clientela quanto os serviços prestados.

Por outro lado, a entrevista semiestruturada e adequação das questões referenciadas no SERVQUAL possibilitam identificar a construção e descoberta de novos significados (para as experiências atuais através do insight) dos desejos e necessidades dos entrevistados. Na realidade, pouco a pouco, o modelo SERVQUAL foi substancialmente reconstruído pela técnica incidente crítico; consoante a condição sine qua non Serrano (2006) aponta o nexo entre desempenho e as exigências de satisfação e insatisfação dos clientes diante vicissitudes torna-se um elemento-chave não apenas para a "sobrevivência" da fundação, mas também para a consolidação da imagem de experiência, tradição e solidez institucional.

$\mathrm{Na}$ presença da esquematização das questões, os foliões deveriam assinalar uma opção entre 1 e 5 da escala Likert para o item "importância" (sendo que na escala $1=$ menos importante e 5=muito importante); para o item "satisfação" (sendo que na escala $1=$ insatisfeito e 5=muito satisfeito); acerca das 22 sentenças: $1,2,3$ e 4 questões referem-se a dimensão tangibilidade; $5,6,7,8$ e 9 referem-se à confiabilidade; $10,11,12$ e 13 à receptividade; $14,15,16$ e 17 à segurança ,e por fim; as sentenças 18 a 22 referem-se à empatia. Em suma, a interpretação dos resultados da pesquisa considera as técnicas estatísticas (análise descritiva). Os dados coletados foram entre os dias dez a trinta de setembro de 2016, 
sendo o instrumento de coleta de dados aplicado após a consulta clínica e o atendimento na ótica; sendo inseridos e tabulados no programa Excel da Microsoft para confecção/organização em tabelas e gráficos descritivos.

Em convergência com Crossno et al. (2001), preferimos utilizar o termo importância ao invés de expectativas, proposto pelo método SERVQUAL, porque essa abordagem teóricometodológica permite ajustes, isso tal, simplifica a compreensão: é mais fácil para o participante entender: "o quanto atendimento é importante para você" do que "qual a sua expectativa em relação ao atendimento". Pela mesma razão, percepção foi substituída por "satisfação" na esquematização das questões.

\section{RESULTADOS}

Um total de 181 respostas foram coletadas, no qual foram considerados apenas os questionários que tinham a resposta "Sim" as questões: "você já consultou na clínica da associação dos cegos e; utilizou os serviços da ótica da associação?". Uma vez que o modelo SERVQUAL exige certo conhecimento e/ou experiência prévia do serviço a ser avaliado. A faixa etária dos participantes variou de 18 a 64 anos de idade, sendo cento e sete indivíduos casados e setenta e quatro solteiros; dentre os casados, três têm cônjuge com cegueira. Todos têm o Ensino Médio completo, e sete entrevistados estão cursando o Ensino Superior.

Quanto ao sexo, $95(59,12 \%)$ eram mulheres e o restante, 74 (40,88\%), homens. Em termos de faixa etária, 66 participantes $(36,46 \%)$ como idade entre $18-29$ anos, e 115 $(63,54 \%)$ participantes como idade entre superior a 29 anos.

Quanto ao município de residência: 143 (79,01\%) são da Mesorregião da Zona da Mata, $16(8,84 \%)$ da Mesorregião do Campo das
Vertentes, 18 (9,94\%) da Mesorregião do Sul Fluminense e, outros $4(2,21 \%)$ residem em municípios da Mesorregião do Sul e Sudoeste de Minas.

Quanto à frequência de utilização, 31 $(17,13 \%)$ dos participantes comparecem na associação regulamente, pelo menos uma vez por bimestre. Destaca-se também que 81 $(44,75 \%)$ frequentam semestralmente. Outros $69(38,12 \%)$ participantes não souberam ou não quiseram responder essa questão.

Uma análise dos resultados permite identificar os itens mais importantes (expectativa) para a maioria dos participantes: "instalações físicas adaptadas às necessidades dos usuários/clientes" obteve $85,64 \%$ das respostas e "Funcionários gentis e acessíveis", $88,40 \%$. Ainda em relação à importância, os itens da pesquisa receberam dos participantes uma pontuação que variava entre 4,46 e 4,83 de uma escala de cinco pontos. Isso sugere que, os fatores selecionados para a pesquisa são de fato relevantes para os clientes da Associação dos Cegos.

Entre os itens indicados como de "maior satisfação", o primeiro deles, com $79,56 \%$ das respostas foi "Funcionários que se comunicam bem". Ainda em relação à satisfação (percepção), os participantes atribuíram às questões, uma pontuação que variava entre 4,12 e 4,63 de uma escala de cinco pontos, apontando uma pequena diferença entre a importância e a satisfação dos serviços. Entretanto, os itens que obtiveram uma pontuação menor podem representar aspectos a serem melhorados nos serviços ofertados pela instituição. Entre eles estão a "Disponibilidade dos equipamentos" e "Atualização e variedade da programação", com respectivamente 11,80\% e $10,20 \%$ das respostas marcadas entre "insatisfeito" e "pouco satisfeito".

A tabela 1 apresenta a média da pontuação (em uma escala de 1 a 5) recebida 
(MIGUEL; FREIRE, 2017)

pelos indicadores da qualidade de serviço a por dimensão:

respeito da importância e satisfação, agrupados

Tabela 1 - Importância e Satisfação por Dimensão

\begin{tabular}{lcc}
\hline Dimensão & Importância & Satisfação \\
\hline Empatia & 4,83 & 4,15 \\
\hline Garantia & 4,46 & 4,20 \\
\hline Receptividade & 4,52 & 4,50 \\
\hline Confiabilidade & 4,66 & 4,12 \\
\hline Tangibilidade & 4,72 & 4,63 \\
\hline
\end{tabular}

Fonte: Dados da pesquisa (Juiz de Fora/MG, 2016)

Verificar as dimensões determinantes da qualidade do serviço apontadas nesse presente estudo assinalaram a dimensão Empatia, sendo a preferida pelos participantes da pesquisa. Empatia, para o método SERVQUAL, pode ser interpretada de modo que a disposição que o funcionário apresenta e manifesta nos cuidados e atenção individualizada prestada a clientela, medindo uma dimensão da qualidade que comporta o know-how (conjunto de conhecimentos práticos - compreende o saber fazer e o domínio especializado) dos funcionários de se colocarem na circunstância do usuário do serviço, vivenciando seus sentimentos e necessidades.

\section{Análises de Gaps e quadrantes}

Brito e Vergueiro (2011) apontam os "Gaps por dimensões" quanto a ferramenta útil para representação dos resultados empregando a seguinte fórmula:

[Gap = Satisfação - Importância $]$

Para calcular as médias, as pontuações (de 1 a 5) de cada questão foram somadas e divididas pelo número total de respondentes tanto para a satisfação quanto para a importância. O Gráfico 1 apresenta os Gaps por dimensão:

Gráfico 1: Gaps por dimensões da qualidade

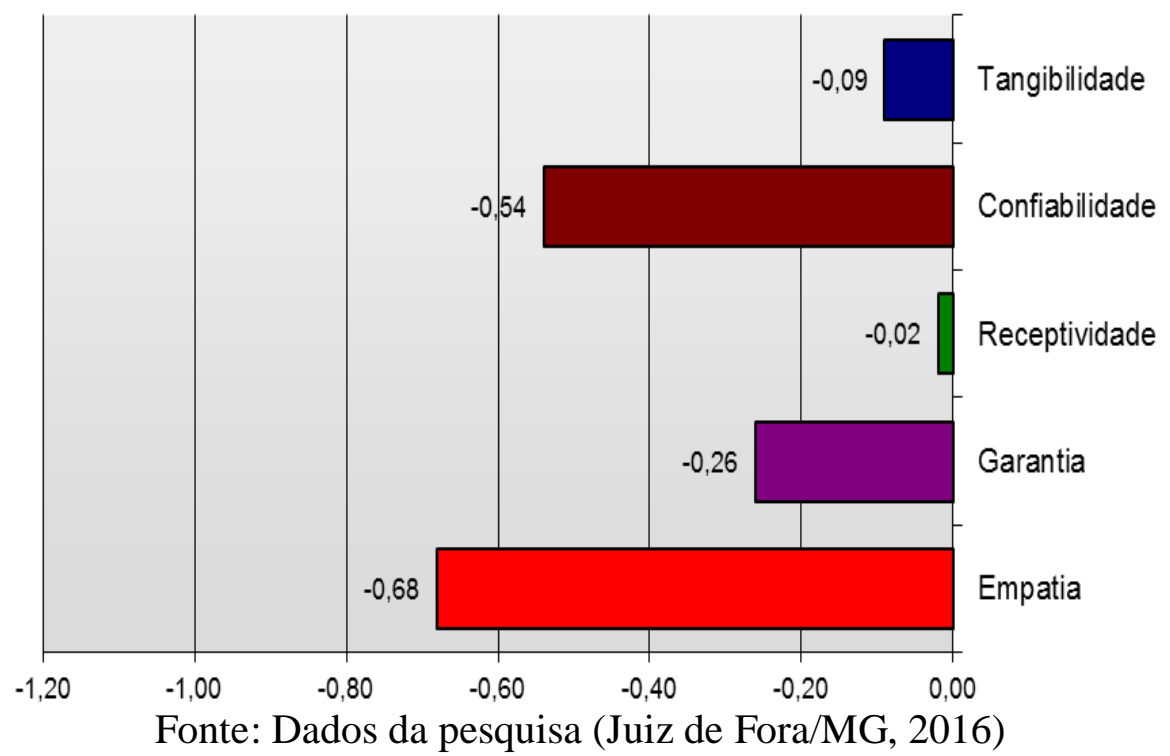


(MIGUEL; FREIRE, 2017)

Já Matriz de Análise de Importância X Desempenho assinala outra forma didática de apresentar os resultados dessa abordagem teórica metodológica. Nitecki e Hernon (2000) recomendam-na porque propicia uma correlação gráfica que facilita a visualização dos dados, obtendo importante diagnóstico. Nessa pesquisa, a Figura 1 posiciona o serviço prestado no quadrante 1 (manter); isso indica um serviço bem desempenhados pelas instituições conforme apontamentos da Figura 1.

Figura 2: Análise de Quadrantes.

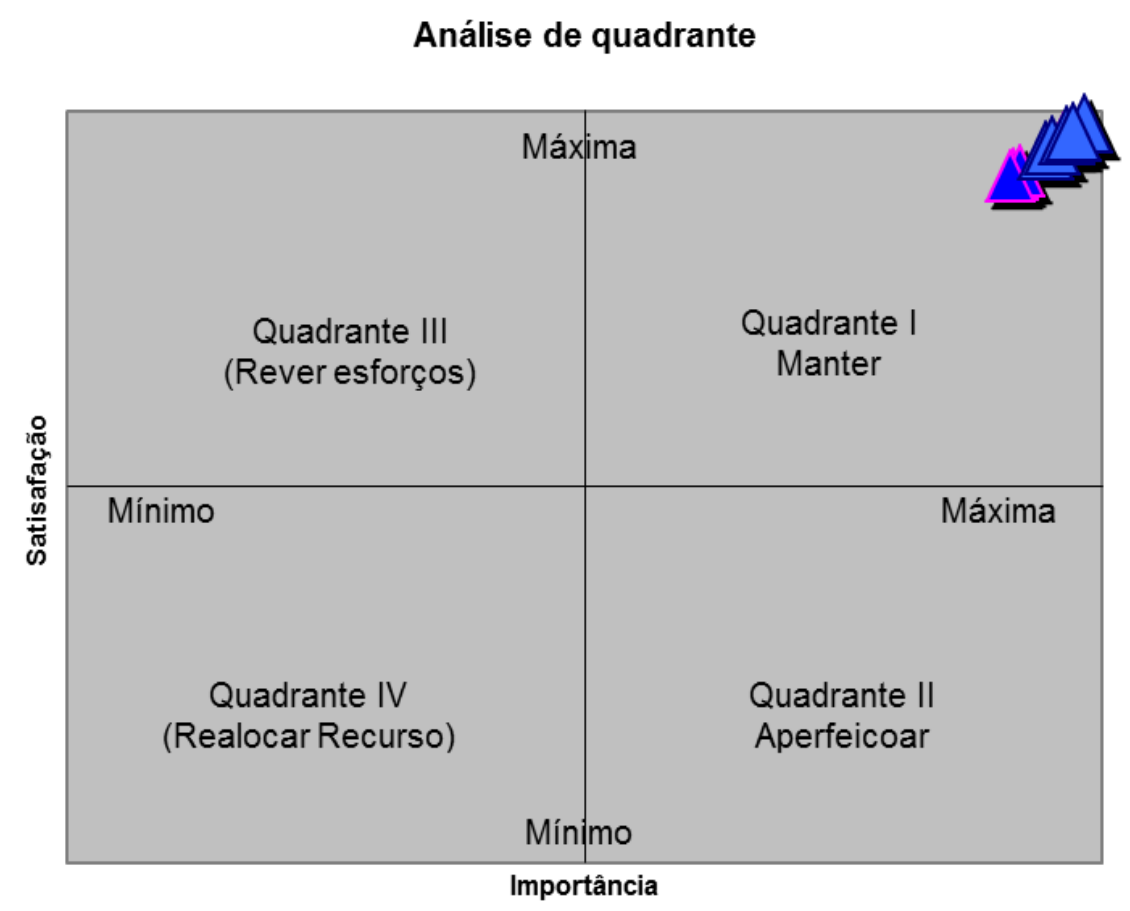

Fonte: Dados da pesquisa (Juiz de Fora/MG, 2016)

\section{DISCUSSÃO}

Verificar Utilizado para avaliar o grau de satisfação dos clientes da Fundação João Theodósio de Araújo (Associação dos Cegos) pode-se também indicar como ponto positivo o fato que esse método "aproxima" essas organizações de seus clientes. Por isso, a avaliação deve ser constante, tendo como metas a captação de nuances das necessidades dos clientes-usuários, da instituição e dos parceiros, visando a implementar as melhorias percebidas pelo estudo realizado.

Portanto, não basta a intenção de fornecer serviços com excelente qualidade. É necessário que, as instituições estruturem processos contínuos para monitorar as percepções dos clientes sobre a sua qualidade de serviços. Porém, deve-se ter em conta que o usuário sempre pode mudar a direção, forma e característica de qualquer serviço, dependendo de suas necessidades.

A partir do Gráfico 1 pode-se deduzir que o item com o maior Gap, maior é a lacuna entre o serviço esperado e o serviço percebido (resultado direto da efetiva prestação do serviço). A comunicação é crucial para a qualidade do serviço, pois influencia não somente a percepção do serviço prestado, similarmente as expectativas quanto ao mesmo.

Nesse cenário vemos que o Gap pode ser definido como a diferença entre o serviço 
desejado e o encontrado. Tangibilidade é a dimensão que apresenta menor divergência, isso ratifica a atuação da Acegos para assegurar um serviço com competência, cortesia, credibilidade e segurança nos que tange seus aspectos e recursos tangíveis.

A Matriz de Análise de Importância X Desempenho (quadrante) constitui-se uma outra ferramenta teórico-metodológica para que a instituição tenha uma visão estratégica sobre quais os atributos deve melhorar, deste jeito, podemos dizer que a análise de quadrantes é uma boa forma de se apresentar os resultados do método SERVQUAL. Nitecki e Hernon (2000) recomendam-na porque propicia uma correlação gráfica que facilita a visualização dos dados conforme observamos na representação gráfica.

Ao aplicar a análise de quadrante verifica-se informações bastante interessantes sobre o serviço prestado pela associação e, nessa pesquisa ocorreu uma concentração no quadrante 1 (manter) de todos os vinte atributos da qualidade. Isso sugere que os entrevistados consideram todos os atributos da pesquisa quão importantes e bem desempenhados pela associação pode ser observando na análise de quadrantes (Figura 1).

Por meio dessa pesquisa foi possível constatar que os usuários percebem positivamente a qualidade dos serviços prestados pela Associação dos Cegos de Juiz de Fora. A diferença entre importância e satisfação foi mínima, indicando que a da Associação dos Cegos está muito perto de atingir as expectativas de seus clientes. Parte dessa alternativa, extremamente viável segundo dos entrevistados comporta a extensão do horário de funcionamento, para poderem retornar e indicando, in totum, que grande melhoria condiz com que é demonstrar interesse e atenção individualizada aos clientes e, uma solução para essa pendência pode incluir treinamento.

Claro está, não obstante, que os profissionais influenciam diretamente na dimensão analisada e, o fato dessa média ser mais baixa alude a questões de um descompasso entre a cortesia e a humanização dos serviços de saúde.

Cabe registrar, ainda que, para conquistar uma melhor qualidade no processo de desenvolvimento e gestão cuidar e sanar cada lacuna são fundamentais; uma vez diagnosticado os hiatos deve a instituições sair da gestão "ortopédica", das medidas "maquiadas" e das "ações paliativas" e, sincronizar a humanização como meta de uma nova cultura institucional que possa implantar padrões de relacionamento ético entre gestores, técnicos e usuários.

Um dos pontos fracos refere-se aos Gaps 5 (figura 2) demonstra a necessidade de se cuidar da confiabilidade, bem como do processo de humanização e acolhimento dos usuários por parte dos colaboradores (Empatia). Berry e Parasuraman (1992) alertam que confiabilidade é o principal fator que os clientes consideram; sendo essa dimensão mais importante para atender as expectativas do serviço diante a visão do consumidor - não percebe a qualidade do serviço. 
(MIGUEL; FREIRE, 2017)

Figura 2: Gap entre serviço percebido e o serviço esperado

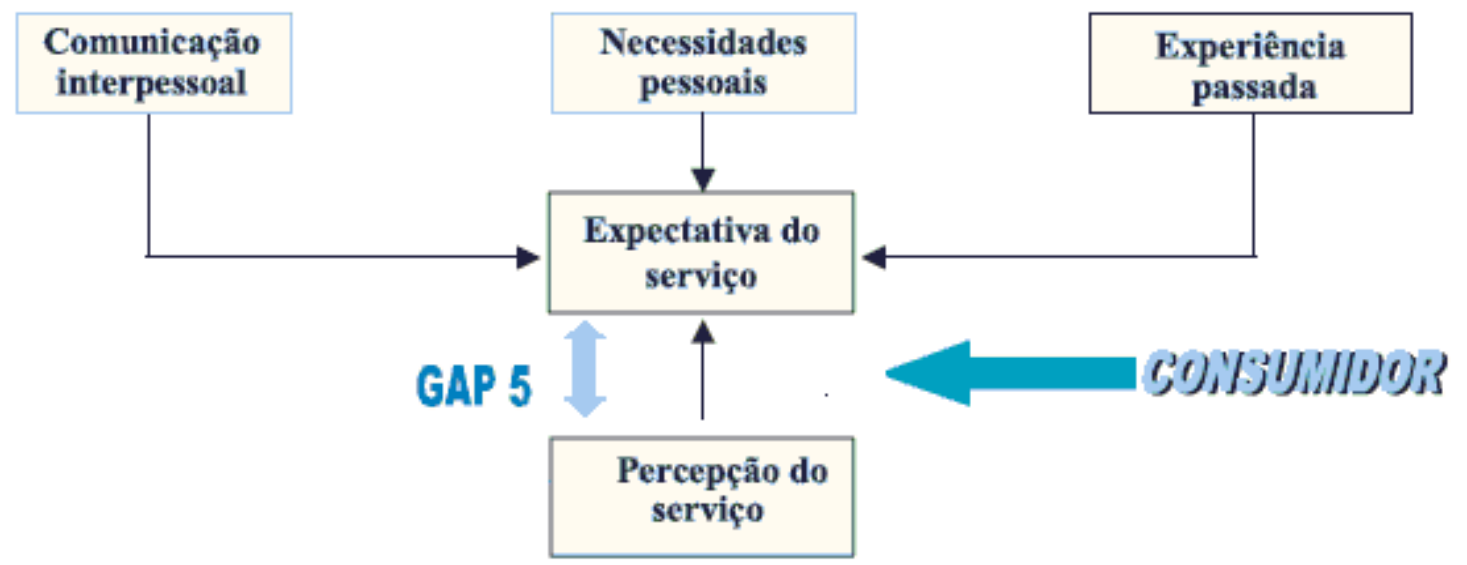

Fonte: adaptado de Parasuraman, Berry e Zeithaml (1985).

Em consonância com essas observações, há outro aspecto interessante que merece ser abordado: a intervenção judicial em 2015. É preciso pensar que a instituição quando abala a relação de confiança com os cidadãos resulta em um descuido: ao deixar de prestar o serviço, atua com pequenos erros evitáveis ou ausenta-se de cumprir o prometido.

Por conseguinte, a estratégia adotada pelo Ministério Público do Estado de Minas Gerais certamente logrou êxito, pois promove transparência a questão. Ao ver a falha da associação administrada pelo Poder Judiciário (para averiguação de possíveis irregularidades/dificuldades de ordem contábil e administrativas) fez cair o numerário das doações.

\section{CONSIDERAÇÕES FINAIS}

Este estudo foi realizado tendo como objetivo principal avaliar a qualidade dos serviços prestados Fundação João Theodósio Araújo, conhecida como Associação dos Cegos, que fica na Avenida dos Andradas, Centro de Juiz de Fora - MG. Em meio às vantagens do método em questão, há uma desvantagem: o questionário padrão do SERVQUAL é constituído apenas por questões fechadas o que o caracteriza como um método quantitativo.

Entretanto, nesse trabalho, buscamos suprir essa lacuna inserindo uma questão aberta. Nessa direção, ao dar voz a clientela também por essa via, além de agregarmos valor qualitativo ao estudo de usuários, reunimos informações explícitas que propiciam o monitoramento organizacional, hoje, tão significativo para o desenvolvimento das instituições.

Assim, pode-se ressaltar que, todo esse elenco de preocupações deve ser levado em consideração, sem se perder de vista que os modelos de avaliação da qualidade de serviço são instrumentos essenciais de aferição de diagnósticos dos pontos fortes e fracos (MIGUEL; FREIRE, 2017), em que podem exprimir oportunidades de aplicabilidade de boas práticas (best practices) e inovação. Quando corretamente implementados e empregados; identificam causas e encontram soluções criativas no processo de tomada de decisão.

O tema não foi esgotado, e outras reflexões podem ser propostas para a Acegos e um amplo rol de instituições. Sugerimos explorar mais a parte qualitativa da abordagem teórico-metodológica SERVQUAL promovendo um diagnóstico minucioso da ambiência e 
também a utilização de outros métodos como o SERVPERF (o qual apresenta um questionário mais reduzido baseado somente na percepção de desempenho dos serviços).

É importante salientar também que, possíveis desdobramentos podem fundamentar uma continuidade nessa linha de pesquisa; em contrapartida, os interessados em replicar este tipo de pesquisa devem-se atentar que a avaliação não é um fim em si.

Por fim, relevante é contribuição deste artigo para desprender algumas lacunas, fornecendo um sucinto panorama da Acegos. Recomendam-se que vindouras investigações apontem questões específicas e reúnam dados sobre: o desempenho, posicionamento político, gestão estratégica, internacionalização, profissionalização, sustentabilidade financeira; grosso modo, assinale as melhorias inward e outward incipientemente reportadas nesse estudo.

\section{REFERÊNCIAS}

ASSOCIAÇÃO DOS CEGOS JUIZ DE FORA. Fundação João Theodósio Araújo. História. 2014. Disponível em: <www.acegosjf.com.br>. Acesso em: 17 out. 2016.

BERRY, Leonard L.; PARASURAMAN, A. Serviços de marketing: competindo através da qualidade. São Paulo: Maltese: Norma, 1992. $238 \mathrm{p}$.

BOBBIO, Norberto. A era dos direitos. Rio de Janeiro: Campus, 1992.

BRASIL. Ministério da Saúde (BR). Assistência Segura: uma reflexão teórica aplicada à prática. Brasília: DF; 2013. Disponível em: <http://www20.anvisa.gov.br/segurancadopacie nte/images/documentos/livros/Livro1-

Assistencia_Segura.pdf $>$. Acesso em: $23 \mathrm{dez}$. 2015.
COSTA FILHO, Costa. Estudo comparativo da qualidade de serviços de instituições de ensino superior de paranavaí. 2012. 102 p. Dissertação (Mestrado). Pedro Leopoldo, 2012.

CROSSNO, J. E. et al. Assessment of customer service in Academic Health Care Libraries (ACSAHL): an instrument for measuring customer service. Bulletin of the Medical Library Association, v. 89, n. 2, pp. 170-176, Abr. 2001. Disponível em: <http://www.ncbi.nlm.nih. gov/pmc/articles/PMC31724/>. Acesso em: 17 jan. 2016.

DEMING, W. Edwards. O Caminho do sucesso II. São Paulo: EncyclopaediaBritannica do Brasil, 1994. 1 vídeocassete (26 min): son., color. (Videopédia Empresarial)

ISHIKAWA, Kaoru. Controle de qualidade total: maneira japonesa. Rio de Janeiro: Campus, 1997. 221p.

JURAN, J. M. A qualidade desde o projeto: novos passos para o planejamento da qualidade em produtos e serviços. 2. ed. - São Paulo: Pioneira, 1994.

MELLO, Carlos Henrique Pereira et al. Gestão do processo de desenvolvimento de serviços. São Paulo: Atlas, 2010. VIII, 194 p. ISBN 9788522459568

MIGUEL, M. C; FREIRE, V. F. Avaliação da Qualidade Orientada ao Usuário do Museu Capixaba do Negro: Aplicação da Abordagem Teórico-Metodológica Servqual em um Espaço Museológico de Vitória-ES. Guará, Vitória, n. 05, p. 103-116, Jul, 2016. Disponível em: <http://periodicos.ufes.br/guara/article/view/14 350/10092>. Acesso em: 19 jul. 2016.

NITECKI, D. A.; HERNON, P. Measuring service quality at Yale's University's libraries. The Journal of Academic Librarianship, Ann Arbor, v. 26, n. 4, p. 259-273, Jul. 2000.

PARASURAMAN, A; ZEITHAML, V. A; BERRY, L. L. A conceptual model of service 
(MIGUEL; FREIRE, 2017)

quality and its implications for future research.

Journal of Marketing, Chicago, v. 49, n. 4, p. 41-50, Fall 1985.

PASCARETTA JÚNIOR, Vicente. A cegueira na humanidade: do mecanismo da visão à catarata. Recife: Liceu, 2008. 